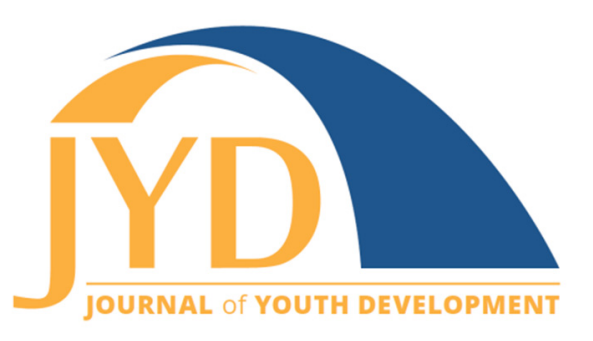

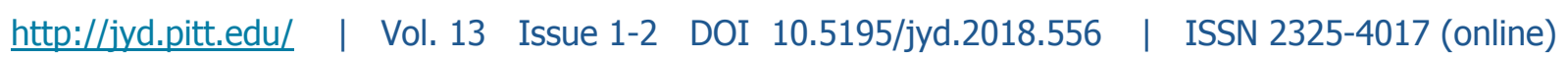

\title{
The Fundamental Characteristics and Unique Outcomes of Christian Summer Camp Experiences
}

\author{
Jacob Sorenson \\ Sacred Playgrounds \\ jake@sacredplaygrounds.com
}

\begin{abstract}
Very little research is available on the unique characteristics and outcomes of Christian summer camps, in spite of their prevalence in the industry. The Effective Camp Research Project is a mixed-methods study seeking to close the research gap. This article presents the major findings of the study, detailing the emergence of a distinct Christian camp model with 5 fundamental characteristics: relational, safe space, participatory, unplugged from home, and faith-centered. A multi-test survey of campers provides compelling evidence for outcomes that are immediate, subsequent, and lasting. Some of these outcomes are common to all camp types, though many are unique to the contextual realities of Christian camps that effectively partner with the ministries of churches and homes. Camper outcomes identified in other studies are interpreted theologically in the context of Christian camps, providing particular relevance to faith communities and people of faith.
\end{abstract}

Key words: camp research, religious camps, Christianity, mixed-methods research

\section{Introduction and Project Rationale}

Research on summer camp has shown a remarkable surge in the past two decades, though specifics of religiously affiliated camps have been largely overlooked in camp scholarship. This oversight is surprising, given the importance of religion in the early camping movement and ongoing prevalence of religiously affiliated camps, which account for as many as a quarter of all camps in the country (Henderson \& Bialeschki, 2008). The disconnect between religious camps and their secular counterparts has deep historical roots that Eells (1986) and other authors have chronicled. She noted that secular camping professionals have often decried the lack of standards at many religious camps while Christian camping professionals have bemoaned the lack of spirituality at secular camps. Religious camps share many of the same characteristics as

(cc) EY $_{\text {EY }}$ New articles in this journal are licensed under a Creative Commons Attribution 4.0 License. This journal is published by the University Library System, University of Pittsburgh and is cosponsored by the University of Pittsburgh Press. The Journal of Youth Development is the official peer-reviewed publication of the National Association of Extension 4-H Agents and the National AfterSchool Association. 


\section{Uniqueness of Christian Summer Camp Experiences}

secular camps even as they maintain important differences that shape program philosophy, clientele, and desired outcomes. This article presents the major findings of the Effective Camp Research Project (ECRP), one of the most comprehensive studies to date on the specific contributions and lasting impacts of religious camps in the Christian tradition.

Garst, Browne, and Bialeschki (2011) have persuasively argued that unique program characteristics are at least as important to camp outcomes as camp settings and structures. This highlights the need to assess outcomes specific to certain camp types. Sales and Saxe (2004) attended to the unique characteristics and outcomes of Jewish camps, demonstrating the fruitfulness of research targeting specific subsets of religiously affiliated camps. Smith (2009) documented the positive effects that lives of faith and connection to religious faith communities have on young people's wellbeing and life outcomes. Religious camps that foster growth in faith and increase connection to religious communities deserve attention as places that foster positive youth development in unique ways.

The characteristic that sets religiously-affiliated camps apart from secular camps is their emphasis on faith. This characteristic is similar to the more commonly assessed outcome of spirituality, which camp scholars have struggled to define and measure. Sweatman and Heintzman (2004), for example, allowed the participants themselves to define spirituality. Henderson and Bialeschki (2008) noted that secular camp experiences often provide the potential for spiritual development "in an implicit and tangential way," and they argued that this dimension of growth is often overlooked. Existing research demonstrates that religiouslyaffiliated camps have stronger outcomes than secular camps on generic measurements of spirituality (Henderson, Oakleaf, \& Bialeschki, 2009), but this research has not attended adequately to camps that give specific theological truth-claims center stage. As Ferguson (2007) argues, "The interconnection between religion and spirituality must be untangled" in order to more fully understand camp's role in nurturing spirituality.

Specific religious truth-claims tie camps closely to the ministries of churches, synagogues, denominational bodies, and other religious organizations. These connections have helped ensure that camp is not a stand-alone experience for most campers but rather part of a larger ecology of religious support and character formation. Religious communities send their young people to camp and reinforce the positive development of the camp experience. The National Study of Youth and Religion (NSYR) found that fully 39\% of all American teenagers had attended a religious summer camp at least once, including more than half of teenagers affiliated with Protestant Christian denominations (Smith, 2005). Secondary analysis of these data found 


\section{Uniqueness of Christian Summer Camp Experiences}

that those youth who attended religious summer camp were significantly more likely to be involved in religious small groups, attend church, and remain affiliated with their religious tradition 5 years later than those youth who did not attend (Sorenson, 2014).

The dearth of information on faith-based camps led to our interest in exploring outcomes and impacts of the camp experience on youth who attend these religiously-affiliated camps. As with Sales and Saxe, we selected a specific subset of religious camping: Lutheran camps. The specific research question explored was: What is the impact of the one-week Christian summer camp experience on the lives of the primary participants and their supporting networks?

\section{Project Overview and Methodology}

This project sought to explore the impacts of a Christian summer camp experience on youth and their support networks. The primary focus was the camper experience, although summer staff members were also considered as a part of the participant group. Supporting networks included adults involved in nurturing and caring for the primary participants, predominantly parents/guardians and church leaders. The project adopted a mixed-methods sequential exploratory methodology with a qualitative phase in 2015 followed by a quantitative phase in 2016. In compliance with the Institutional Review Board of Luther Seminary in Minnesota, numerous ethical considerations were followed to ensure the safety of the study participants.

The qualitative portion (Sorenson, Hill, and Middlesworth, 2016) began with a sample of three Lutheran camps in Wisconsin, all accredited by the American Camp Association. Limiting the sample to a narrow geographic region and denominational family eliminated many intervening variables and prioritized rich description over broad generalization. The aim with this methodological approach was to begin with a very focused sample, establish theory, and then begin testing the theory with ever broader and more generalizable samples. For these reasons, the qualitative phase of the study used grounded theory, which grounds the data in the perspectives and specific vocabulary of the research subjects. This phase had six data streams: an interview with the camp director; a 4-day site visit with direct observation and field notes; focus groups with summer staff members, campers (one male group and one female group), and area church professionals; and a survey of camper parents following the camp experience. The target camper age group was 11 to 14 years. Open-ended question responses from the 386 parent surveys were coded along with the field notes and transcripts from the three interviews and 12 focus groups. Three separate researchers coded the material to ensure interrater reliability. The coding process followed Charmaz's methodology of initial coding, focused 
coding, axial coding, and theoretical coding (Charmaz, 2005). From these data streams emerged five fundamental characteristics of the Christian camp experience, which become the foundation for the proposed Christian camp model. Phase 1 participants also identified numerous outcomes of the camp experience that were further assessed in the subsequent phase.

The quantitative phase 2 (Sorenson, 2017) used a series of questionnaires derived from the findings of the grounded theory phase. This phase expanded the sample to six camps, including the original three, and surveyed campers on the first day, last day, and two to three months following the camp experience. The questionnaires focused heavily on the faith-related camp outcomes identified in phase 1 , although they also included items related to self-confidence, social skills, and other outcomes commonly identified in camp literature. Half of the items (17) were identical on all three questionnaires in order to assess change over time. The remaining items were related to demographics, motivation for attending (first day), home and church life (first day), enjoyment of the experience (last day and follow-up), and direct questions about outcomes (last day and follow-up). Questionnaires were field tested prior to use. The criteria for the sample remained Lutheran camps in Wisconsin, with the added provision that they must serve a minimum of 200 summer campers ages 11 to 14. All eligible campers had an equal chance of participating in the survey, with the only selective criteria being obtainment of parental consent and camper consent. This process resulted in 1,187 survey participants. This sample was majority female (57\%), and predominantly white $(92 \%)$ and Lutheran $(90 \%)$. The match between pre-camp and post-camp test completions was $86 \%$ of respondents; the match rate for the electronically distributed follow-up survey was $25 \%$. However, because email addresses were unavailable for some of the campers, the actual response rate to the follow-up survey was $33 \%$. Survey data were analyzed with a variety of statistical tests, including descriptive statistics and t-tests, using SPSS Statistics software.

\section{Phase 1 Findings}

Five fundamental characteristics of Christian summer camp emerged from the perspectives of the campers, staff members, parents, and area church leaders in the qualitative phase of the study (2015): safe space, relational, unplugged from home, participatory, and faith-centered. No set order or direction of influence existed among these characteristics. They interacted dynamically with the lived experience of each individual camper. If one characteristic broke down, the whole experience fundamentally changed to the point where it was no longer recognizable as camp. All negative comments about the camp experience were associated with 
Uniqueness of Christian Summer Camp Experiences

a breakdown in one or more characteristics of the proposed Christian camp model (see Figure 1). Each of these characteristics in the model is briefly described here.

Figure 1. Five Fundamental Characteristics of Christian Camp

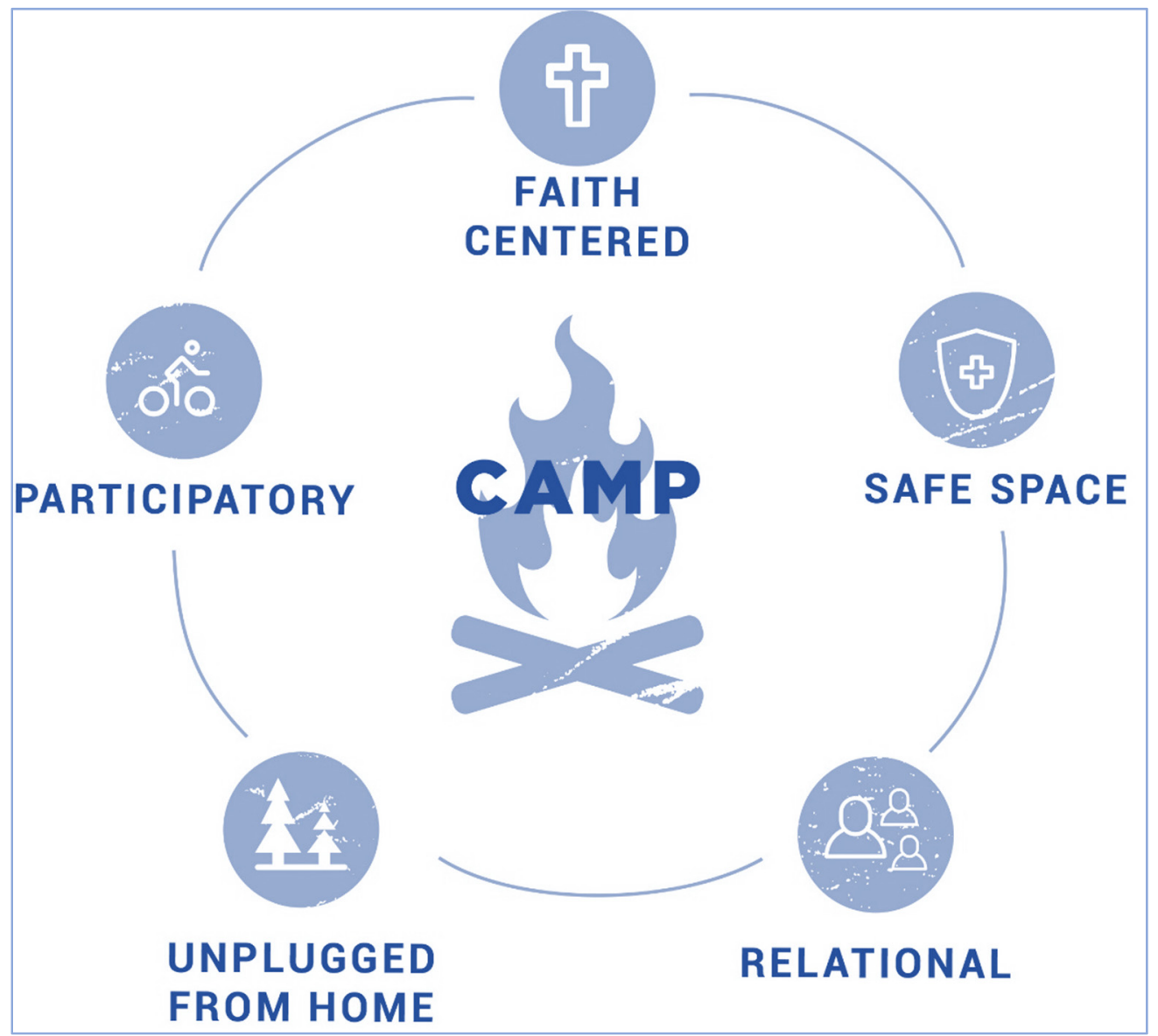

\section{Relational}

Relationality is the most recognizable characteristic of the Christian camp model. This characteristic is commonly found across the literature among all camp types (American Camp Association, 2006) and was clearly present at the sites studied. Participants played, prayed, ate, slept, worked, and worshiped together. Programs at each of the camps featured intentional community-building activities such as low ropes courses and cooperative games. Personal relational encounters occurred including daily small group Bible studies at each of the camps, evening devotions in the sleeping areas, and numerous one-on-one conversations. Campers and staff members frequently described how they fit in at camp. One female camper explained, 


\section{Uniqueness of Christian Summer Camp Experiences}

"We're all so different, but we all came together, and it was a puzzle that fit perfectly together. Like a 500-piece puzzle you just put together for the first time." Among parent respondents, $91 \%$ agreed that their child made friends at camp, and 92\% agreed that their child met an adult role model.

\section{Safe Space}

The characteristic camp is a safe space included physical, emotional, and spiritual safety. Signs of physical safety were the most outwardly apparent in the site visits, and fully $94 \%$ of parent respondents agreed that their children's physical needs were taken care of at camp. However, the data revealed that emotional and spiritual safety were equally important. The rare breakdowns in this safety characteristic were not due to concerns of physical safety but rather when campers felt left out or had to hide their true selves. The theme of judgment was common in the camper and staff focus groups to describe exclusion or ridicule experienced away from camp, particularly at school. One male camper described the emotional and spiritual safety of camp, "I feel like no one will judge you because of what you believe here. That's why I like it." Feeling safe helped strengthen the relational bonds among campers and facilitated their openness to new experiences and the faith-centered nature of the camp environment. One girl explained, "You can openly talk about your faith. You don't have to not say anything." All three camp visits had examples of campers feeling safe to try new things or pray out loud for the first time.

\section{Participatory}

The importance of the characteristic camp is participatory was evident in participant responses and the prevalence of kinesthetic, multi-sensory activities at the site visits. Eighty-seven percent of parent respondents agreed that their child tried something new at camp. Some of these experiences were novel activities like horseback riding, canoeing, or ropes courses, while other activities were familiar games like gaga ball, basketball, or capture the flag. The campers recognized that these activities were active and youth-focused, in contrast to other contexts like church or the classroom that were generally characterized as sitting still and receiving information passively. The games and activities had intentional didactic functions that were clear to the participants. "They're teaching us things without us really knowing that we're being taught," one female camper remarked, adding, "There's always a point to the games." 


\section{Uniqueness of Christian Summer Camp Experiences}

All camps are designed to be participatory, but this characteristic took on theological significance at these Christian camps. Many of the young people had never prayed out loud, read scripture to others, or helped to lead worship services, but these activities were common in these camp environments. They learned the language and practices of faith by actually doing them. "It makes you feel like you're actually a part of it," one male camper explained about the ability to move, dance, and participate in the worship services. Campers worshiped in multisensory environments like campfire circles, in swimming pools, under the stars, and atop a high-ropes climbing tower. Each of these settings added to their awareness of specific aspects of the worship service and helped them actively engage in the experience. One camper reflected on sleeping outside for the first time, "It was amazing to look at the stars and see the moon and know that God created everything, and God created all the beauty." She experienced something new to her that brought her up short, and because she was in a faith-centered community, she interpreted the experience through the lens of faith.

\section{Unplugged from Home}

This characteristic of overnight camps is well documented in the literature and lauded for its developmental potential (Thompson, 2012). In the present study, this characteristic included physical aspects like novel settings and new sleeping arrangements, but the most frequently noted contrasts were social and relational. "Once you actually get away from your life, you can see a whole different angle, and it can be a lot more fun and exciting," one girl noted. Participants relished an increased sense of ownership of their actions and opportunities for decision-making away from the watchful eyes of parents and expectations of their school peers. A female camper said, "You get treated like a person rather than like a little kid." This increased agency and independence extended to the campers' faith lives. One girl explained, "I feel like the counselors help us grow in our faith with Jesus. Even though they help us with that, I feel like we take on our own responsibility, too. We can grow in our faith on our own, independently."

One of the most distinct differences from home that participants described was that they were literally unplugged from technology, particularly social media, cell phones, television, and video games. Surprisingly, the overall assessment of the absence of technology was positive. One camper said, "If you look around you in the city, you'll see a bunch of people walking really fast, talking on their phone...you don't really see people just stopping and looking around at the world, and camp has given us a chance to do that." 


\section{Uniqueness of Christian Summer Camp Experiences}

\section{Faith-Centered}

This characteristic sets Christian camps apart from their secular counterparts. The rhythm of daily Christian living included Christian devotional practices in the morning and at bedtime, a Bible study, and at least one worship service. Faith practices were not compartmentalized from games and other activities but rather infused in every aspect of the programs. A female camper explained,

No matter what we're doing, they intertwine the Christian stuff into it. When we were canoeing, it was about God's water. When we're doing the high ropes, it's our trust that God won't let us fall and our teammates won't let us fall. Wherever we go, we try to see God in whatever we're doing.

It was clear that the combination of the faith-centered environment with the other fundamental characteristics of camp helped to change many participants' perspectives on living a life of faith. Some grasped for the first time an understanding that faith expressions should be participatory, relational, and even fun. As one boy said, "I feel as though praising God isn't a thing that I hate doing anymore. It's a lot more fun. I haven't been doing it, really going to church. I see why we do it now."

These faith aspects were not entirely new to the camp participants. Fully $94 \%$ of parent respondents agreed, "It is important to me that Christian beliefs and practices are emphasized at this camp." The vast majority of campers had a connection to a faith community and participated in at least some Christian practices in the home, so the camp experience served to augment and strengthen these positive aspects of the young people's spiritual lives. The programmatic goals of these camps did not center on Christian conversion but rather on accompanying the young people in their lives of faith.

As the five characteristics emerged from the qualitative data, a related secondary theme emerged around change. These five fundamental characteristics interacted with the unique experiences of each individual camper to provide the space for change to take place. Some campers or their parents described the camp experience as life changing, while they more frequently made claims of less dramatic impacts or no significant impacts at all. One parent survey response is instructive of how the Christian camp model plays out in the life of a unique individual: 
Journal of Youth Development | http://jyd.pitt.edu/ | Vol. 13 Issue 1-2 DOI 10.5195/jyd.2018.556

Uniqueness of Christian Summer Camp Experiences

Her mom is going through a divorce. She was sad and anxious but wanted this camp experience. She made friends, learned how to pray, learned about faith and was uplifted and healed throughout the week. It was one of the best weeks of her life according to her: "I'm not depressed, my appetite is back, I believe I can make friends in a new school, I am closer to God." This camp experience for her was the best!

All five fundamentals of the Christian camp experience are evident in this description, operating in conjunction with the particular contextual realities of the camper. She had powerful impacts from the camp experience in part because of the uncertainties and anxieties she had in her home situation. Separation from the difficulties of home gave her a new perspective on those challenges and an opportunity to restructure her personal narrative in light of the unique atmosphere of camp. She found at camp a safe space where she was "uplifted and healed" from her sadness and anxiety with help from the relationships she formed with new friends. She participated in forms of prayer that were new to her, helping to facilitate a deeper relationship with God. The parent offers a direct quote from the camper identifying substantial impacts on her emotional, physical, psychosocial, and spiritual well-being.

Parent respondents (92\%) overwhelmingly agreed with the statement, "It is clear that camp had an impact on my child." Interestingly, they reported not always looking for or expecting lasting impacts. They were more interested in what might be considered immediate outcomes, such as wanting their children to have fun, be safe, and make friends. It was okay with them that fun was confined to the camp environment and that friendships did not last long-term. Most parents liked their children just the way they were and were not particularly interested in seeing dramatic changes.

Somewhere in between the accounts of life changing experiences and the focus on immediate outcomes are the majority of camper experiences that parents, campers, and staff members described in the ECRP. These outcomes can be differentiated as subsequent outcomes and lasting outcomes. Subsequent outcomes continue to affect campers when they return to their home environment and extend immediately to their supporting networks but generally do not last more than a week or two. Examples of these outcomes included campers being more helpful around the house, nicer to family members, singing camp songs, and generally displaying more happiness, or "zest for life," as one parent put it. Subsequent outcomes are sometimes characterized among church workers (e.g. Yust, 2006) as a camp high that fades 


\section{Uniqueness of Christian Summer Camp Experiences}

quickly after the experience. The fallacy is in assuming that all camp outcomes are temporary simply because some impacts fade after a few days. Many parents, staff members, and campers identified lasting outcomes that continued affecting campers for many months following the camp experience. They spoke of increased engagement in church, more frequent personal faith practices (e.g., Bible reading), greater self-confidence, and a lasting awareness of the importance of faith in everyday life.

The Christian summer camp experience at the camps studied in phase 1 showed evidence of positive impacts, many of which extended beyond the temporary high of a week of camp, affecting devotional practices, church participation, personal well-being, and faith commitment. These impacts were clear and recognizable when camps attended to the five characteristics that emerged from the research as fundamental to Christian camping. Since campers themselves were able to articulate the identified outcomes, researchers hypothesized that these outcomes could be measured using a pre- and post-camp survey, which became the basis for the second phase of the study. The sample was expanded to more than a thousand campers at six camps in order to examine the frequency and extent of the identified outcomes of the Christian camp model in various contexts, including an examination of model breakdowns.

\section{Phase 2 Findings}

Campers completed questionnaires on the first day, last day, and two to three months following camp. The camp experience was, for the vast majority of these campers, part of a much larger ecology of faith formation designed to supplement the work of caring adults in their homes and churches. More than $80 \%$ of campers had attended multiple church services in the two months preceding camp, and $93 \%$ agreed on the first day of camp with a theological statement as specific as, "I believe Jesus rose from the dead." They also came to camp expecting to grow in their faith with $82 \%$ agreeing that growth in their faith was a motivating factor, which was higher than the $69 \%$ motivated to attend camp to meet people or make new friends. A third of the campers (34\%) were attending as part of a formal Christian education program in their church, and over half (59\%) reported that an adult from their congregation visited them while they were at camp.

The five fundamental characteristics of the camp model were present for the vast majority of survey participants, as measured by specific questions (e.g., "I felt safe and happy at camp" and "I got along really well with my cabin group and counselor"). These campers exhibited growth in multiple camp outcomes, though this growth was not present in the small group of campers that showed evidence of one or more characteristics of the camp model breaking 
Uniqueness of Christian Summer Camp Experiences

down. For example, some campers experienced a breakdown in the characteristic safe space. These campers that reported being picked on or left out at least sometimes (7\%) or reported feeling like they had to hide their true selves at least sometimes (8\%) exhibited no growth in measurements of camp outcomes related to the five characteristics in the Christian camp model.

Figure 2. Examples of Camper Impressions of the Camp Experience, Last Day ( $N=$ 1134)

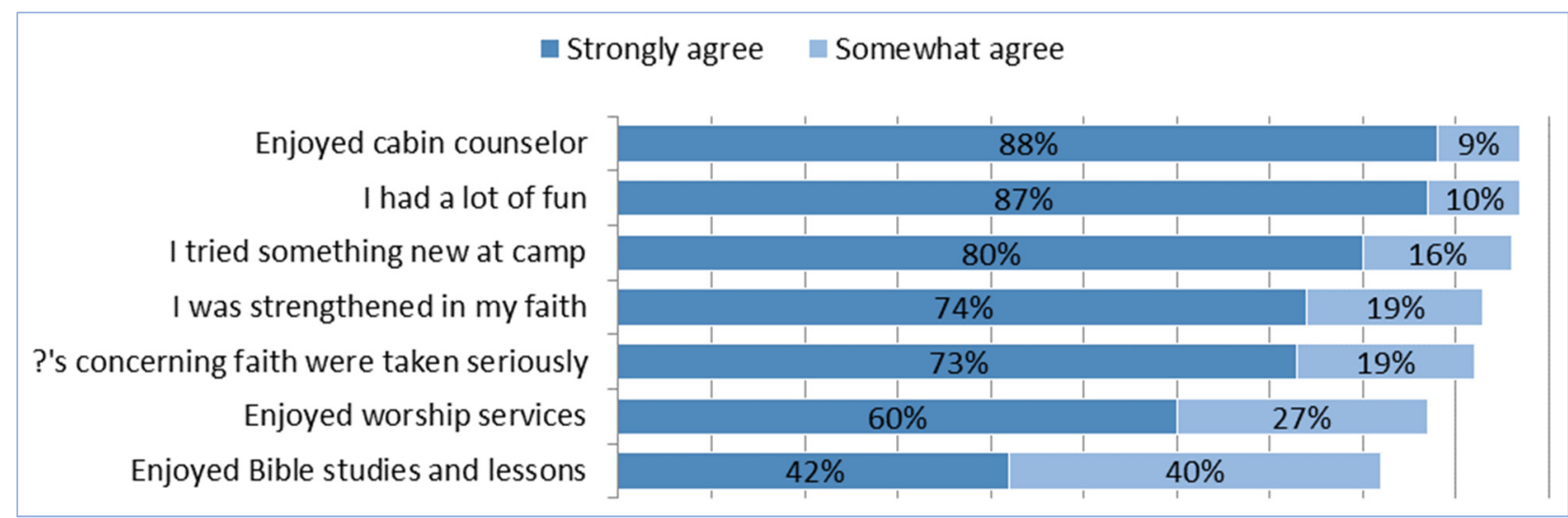

\section{Measuring Subsequent and Lasting Outcomes}

In addition to simple questions of enjoyment and impressions of growth on the last day survey (see Figure 2 for examples), the three camper questionnaires contained 17 identical questions rated on a five-point agreement scale (see Table 1). Sixteen of these items showed significant positive growth from pre-test to post-test as measured during the camp experience. Of the items that showed growth, six regressed to pre-camp levels in the follow-up survey (shown in italics), while the remaining ten maintained the growth observed at camp (shown shaded). This simple analysis offered evidence of the so-called camp high, along with stronger evidence for lasting outcomes. Notice, for example, that one of the six items showing the pattern of postcamp regression was, "I am happy about my life and who I am," indicating the temporary bump in happiness and self-perception that was observed in the qualitative phase. 
Journal of Youth Development | http://jyd.pitt.edu/ | Vol. 13 Issue 1-2 DOI 10.5195/jyd.2018.556

Uniqueness of Christian Summer Camp Experiences

Table 1. Comparison of First- and Last-Day Mean Responses for 17 Identical Survey Items

\begin{tabular}{|c|c|c|c|c|c|}
\hline Survey item & $\mathbf{n}$ & $\begin{array}{l}\text { First } \\
\text { day } \\
\text { mean }\end{array}$ & $\begin{array}{l}\text { Last } \\
\text { day } \\
\text { mean }\end{array}$ & DM & t value \\
\hline Worship services are usually boring. & 952 & 2.59 & 2.18 & -.405 & $-9.605^{* * *}$ \\
\hline I like going out of my comfort zone and trying new things. & 959 & 3.78 & 4.08 & .302 & $9.586 * * *$ \\
\hline Being in nature helps me feel closer to God. & 937 & 3.86 & 4.13 & .274 & $8.849 * * *$ \\
\hline I know that I can make friends. & 963 & 4.57 & 4.74 & .173 & $7.782 * * *$ \\
\hline I have important things to offer the church and the world. & 901 & 4.17 & 4.35 & .173 & $6.457 * * *$ \\
\hline Faith in God helps me in my daily life. & 945 & 4.17 & 4.33 & .157 & $6.065^{* * *}$ \\
\hline $\begin{array}{l}\text { If I have personal problems, there is an adult in my } \\
\text { church I could turn to. }\end{array}$ & 915 & 3.99 & 4.20 & .212 & $5.854 * * *$ \\
\hline $\begin{array}{l}\text { It is important for me to belong to my } \\
\text { church/congregation. }\end{array}$ & 944 & 4.35 & 4.47 & .112 & $4.776 * * *$ \\
\hline I have Christian friends I can turn to in times of need. & 898 & 4.13 & 4.27 & .139 & $4.306 * * *$ \\
\hline I believe that Jesus rose from the dead. & 953 & 4.73 & 4.79 & .062 & $3.503 * * *$ \\
\hline Games and activities usually don't teach me very much. & 949 & 2.28 & 2.14 & -.137 & $-3.248^{* *}$ \\
\hline I believe in God & 952 & 4.85 & 4.88 & .037 & $3.171^{* *}$ \\
\hline God created the world. & 962 & 4.71 & 4.76 & .050 & $3.152 * *$ \\
\hline $\begin{array}{l}\text { When I grow up, I plan to participate in the life of a } \\
\text { church/congregation. }\end{array}$ & 894 & 4.15 & 4.23 & .084 & $3.084 * *$ \\
\hline I am good at solving problems with a team of people. & 953 & 4.04 & 4.13 & .087 & $3.034 * *$ \\
\hline I am happy about my life and who I am. & 957 & 4.73 & 4.77 & .045 & $2.564 *$ \\
\hline I have trouble getting along with and working with others. & 944 & 1.80 & 1.79 & -.007 & -0.187 \\
\hline
\end{tabular}

$* p<.05, * * p<.01, * * * p<.001$

Note: Shaded items maintained the growth observed at camp in the follow-up survey. Items shown in italics regressed to pre-camp levels in the follow-up survey. 


\section{Uniqueness of Christian Summer Camp Experiences}

In order to better differentiate subsequent from lasting outcomes, researchers used exploratory factor analysis to extract a series of indices from the identical survey responses. Three factors were extracted, each including three survey items. The first was termed vertical faith, which included cognitive belief statements. The three items in this factor were "I believe in God," "God created the world," and "I believe that Jesus rose from the dead" (Cronbach $a=.841$ ). The second factor included faith statements that indicated a faith relevant to daily life and reaching out to the surrounding world. This factor was termed horizontal faith and included the items "Faith in God helps me in my daily life," "It is important for me to belong to my church/congregation," and "I have important things to offer the church and the world" (Cronbach $a=.798$ ). The third factor included items related to social skills and self-esteem and was summarized as self-confidence. This factor included "I know that I can make friends," "I am good at solving problems with a team of people," and "I am happy about my life and who I $a m^{\prime \prime}$ (Cronbach $\left.a=.581\right)$. The resulting indices are sums of the component Likert scores, reduced to eight-point scales.

Figure 3 shows the average values of the indices for the campers that completed all three surveys. Vertical faith showed significant growth from the first day of camp to the last day ( $p<$ $.001)$ followed by significant decline to near pre-camp levels by the follow-up survey $(p<.01)$. Both horizontal faith and self-confidence also showed significant growth from the first to the last day of camp (in both cases, $p<.001$ ) but showed no significant change from the last day of camp to the follow-up survey, indicating that the growth was maintained.

Figure 3: Average of 3 Factors, Measured Over Time

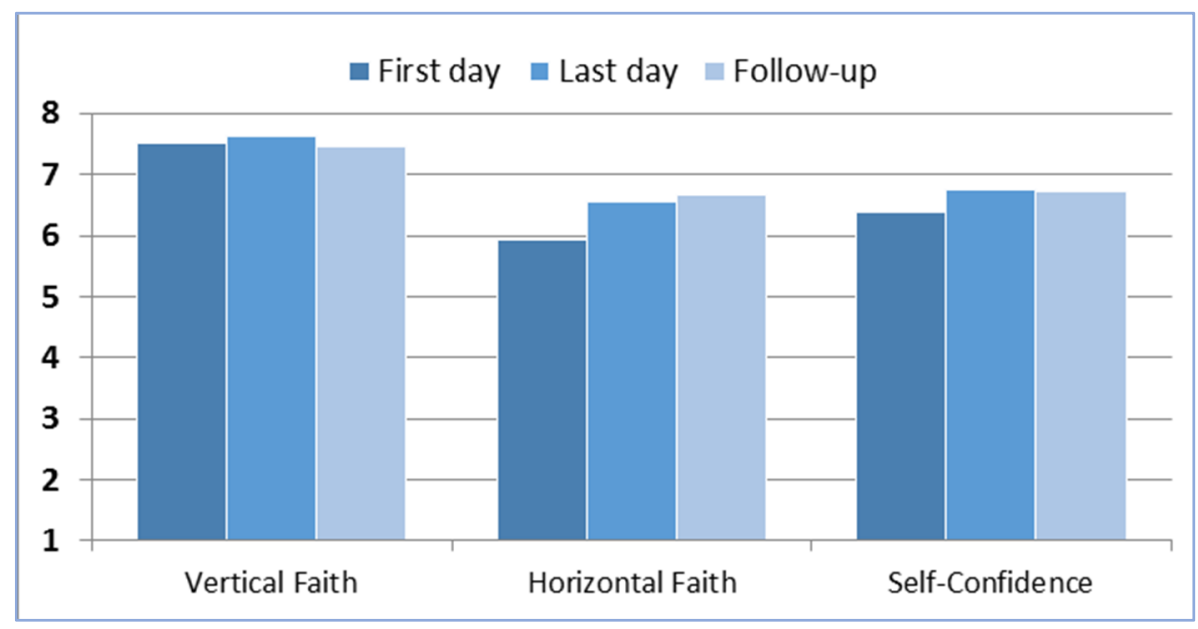


Long-term growth in self-confidence is a common finding in camp research (Thurber, Sanlin, Scheuler, \& Henderson, 2007), indicating that the Christian camps in this study shared key characteristics and outcomes with the larger camp industry. Campers confirmed this growth in self-confidence beyond camp when $82 \%$ agreed on the follow-up survey, "I feel more confident in myself since returning from camp" and $81 \%$ agreed, "Camp helped me grow in independence." Lasting outcomes related to faith are expected in religiously-affiliated camps, and the follow-up survey indicated that $96 \%$ of campers agreed, "I was strengthened in my faith." The ECRP findings went beyond the general notion of spirituality common in other camp studies and delved into the specific qualities of faith demonstrating growth. Belief in specific theological statements showed only a temporary increase, but identification with faith communities and understanding that faith mattered in campers' lives evidenced growth beyond the actual camp experience.

As evidenced by phase 1 findings, these Christian camps provided an effective container for meaningful relationships important to positive youth development. The findings from phase 2 demonstrated that the special connections Christian camps have with congregational ministries serve to strengthen relationships with caring adults outside the camp environment, particularly church workers and faith mentors. One of the items included in all three surveys was, "If I have personal problems, there is an adult in my church I could turn to." This item increased significantly from the first day of camp to the last day $\left(t_{912}=5.854, p<.001\right)$ and remained at an increased level at the two-month follow-up.

Campers also showed increases in Christian practices following the camp experience. In the two months following camp, campers reported increased average church service attendance, Bible reading, and praying with their family compared with their reports of the two months preceding camp. Of the participants who reported on the first day of camp "rarely or never" having conversations with their family about God and faith (27\%), $60 \%$ reported having multiple faith conversations with their family in the 2 months before the follow-up survey. These specific faith outcomes were closely related to the items in the horizontal faith index. It is evident that the Christian camp experience facilitated living the Christian faith (orthopraxy) more than knowing the right things (orthodoxy). This finding makes sense in light of a body of research that has demonstrated the importance of experiential learning in the outdoors over methods of direct instruction on long-term positive life impacts (Daniel, 2007), spiritual development (Heintzman, 2010), and religious education (Jarvis, 2008). 


\section{Discussion}

The Effective Camp Research Project has begun to fill a gap in the research related to religiously-affiliated summer camp. In many ways, the project confirms the findings of other studies that have shown positive and lasting impacts of the summer camp experience on multiple outcomes (American Camp Association, 2005). The five fundamental characteristics of the Christian camp model closely resemble camp descriptions proposed by other scholars, such as the essential trinity of organized camping: community living, away from home, in an outdoor recreational environment (Thurber et al, 2007). It is clear from these findings that the sites studied are recognizably camp, as defined in the scholarly research. However, strong evidence also suggested that these particular camps see themselves as different with unique goals that shaped their programs and outcomes. The most fundamental difference was the characteristic we have identified as faith-centered. Our findings indicated that this aspect was not simply an extra element of the camp experience but rather that faith permeated all aspects of camp. If the faith-centered characteristic was absent or broke down, the experience was no longer recognizable as camp to the campers and staff members.

Outcomes common in all camp types, such as increased independence and self-confidence, were present in these Christian camps, along with faith-based outcomes like faith formation and spiritual practices. These Christian outcomes were related to spirituality but were far more specific, because they intentionally connected campers to the faith traditions present in their homes and congregations. This specificity enhanced relational connection with caring adults outside the camp environment and facilitated such positive communal practices as family prayer, religious service attendance, and conversations with family about faith. The strength of these faith-based outcomes confirmed the findings of previous studies that have demonstrated the importance of program priorities, staff training, and partnerships with other organizations to achieve desired outcomes.

It is interesting to observe that parents in this study were not particularly interested in seeing dramatic changes in their children. It was enough for most of these parents to know that their children were safe and having fun at camp. Some directors tend to promote camp as a lifechanging experience and emphasize the substantial impacts that they have seen in particular campers. They would do well to note that parents might not be looking for life-change but rather for less dramatic impacts. The findings of this study point to camp's role not as a standalone experience but rather as part of a much larger ecology of faith formation and character development in partnership with families and congregations. Impacts considered life-changing 
Uniqueness of Christian Summer Camp Experiences

were identified only rarely. Camps may learn from this finding to emphasize partnership and accompaniment more than life-change.

These findings have other important implications for camp practitioners. Positive camp outcomes are not automatic but rather are dependent on a dynamic interplay of key characteristics. Attention to each characteristic is necessary to ensure the integrity of the camp model. If one characteristic breaks down, the entire camp model breaks down, resulting in outcomes that are less evident or absent entirely. Faith-based camps can use the model constructed based upon the five characteristics that emerged from this study as the basis for program assessment and improvement. Importantly, this model includes faith that is grounded theologically and incorporated into all aspects of camp life. Yust (2006) noted that many Christian camps compartmentalized faith aspects from other camp activities and critiqued such camps as largely resembling secular camps with a "spiritual gloss." The camps she observed exemplified a breakdown in the faith-centered characteristic. Camps that try to achieve outcomes related to a more general notion of spirituality can also glean wisdom from these findings. They may consider how their spiritual priorities can be more fully integrated into all aspects of camp rather than compartmentalized.

The study through 2016 was limited to the state of Wisconsin and the Lutheran denomination. The research project is ongoing, with the data pool expanding to other regions of the country and other Christian denominations interested in assessing the Christian camp model among other faith traditions. Future studies should examine more closely the impact of the summer staff experience at Christian camps and assess the factors that contribute to an understanding of life changing outcomes. In addition, ongoing research is needed to assess the differences between general notions of spirituality at camp and faith grounded in specific theological traditions and connected to faith communities.

This project represents a starting point for a new trajectory in camp studies, focusing on the often overlooked contributions of religious camps. The project is related to and builds from the exemplary work being done among all types of camps. This study has uncovered important commonalities among secular and religious camps and has also identified unique characteristics and outcomes of Christian camps. This project highlights the importance of attending to the unique strengths and characteristics of specific camps in achieving desired outcomes. Camp directors and other youth practitioners can learn more about their industry and the uniqueness of their own work by seeking appreciation for both what unites them with their colleagues and what sets them apart. 
Journal of Youth Development | http://jyd.pitt.edu/ | Vol. 13 Issue 1-2 DOI 10.5195/jyd.2018.556

Uniqueness of Christian Summer Camp Experiences

\section{References}

American Camp Association. (2005). Directions: Youth development outcomes of the camp experience. Martinsville, IN: American Camp Association.

American Camp Association. (2006). Inspirations: Developmental supports and opportunities of youths' experiences at camp. Martinsville, IN: Author.

Charmaz, K. (2005). Constructing grounded theory: a practical guide through qualitative analysis. Los Angeles: SAGE.

Daniel, B. (2007). The life significance of a spiritually oriented, outward bound-type wilderness expedition. Journal of Experiential Education 29, 386-389.

Eells, E. (1986). History of organized camping: The first 100 years. Martinsville, IN: American Camping Association.

Ferguson, N. (2007). Camps and spirituality. Camping Magazine.

Garst, B., Browne, L., and Bialeschki, M. D. (2011). Youth development and the camp experience. New Directions for Youth Development 130, 73-87.

Heintzman, P. (2010). Nature-based recreation and spirituality: A complex relationship. Leisure Sciences $32,72-89$.

Henderson, K. and Bialeschki, M. D. (2008). Spiritual development and camp experiences. New Directions for Youth Development 107-110.

Henderson, K., Oakleaf, L., and Bialeschki, M. D. (2009). Questions raised in exploring spiritual growth and camp experiences. Leisure/Loisir 33, 179-195.

Jarvis, P. (2008). Religious experience and experiential learning. Religious Education 103, 553-567.

Sales, A. and Saxe, L. (2004). How goodly are thy tents: summer camps as Jewish socializing experiences. Lebanon, $\mathrm{NH}$ : Brandeis University Press.

Smith, C. (2005). Soul searching: the religious and spiritual lives of American teenagers. New York: Oxford University Press.

Smith, C. (2009). Souls in transition: the religious and spiritual lives of emerging adults. New York: Oxford Press.

Sorenson, J. (2014). The summer camp experience and faith formation of emerging adults. The Journal of Youth Ministry 13, 17-40.

Sorenson, J. (2017). Effective camp research project, phase 2 report. www.effectivecamp.com.

Sorenson, J., Hill, A., and Middlesworth, K. (2016). Effective camp research project, phase 1: narrative summary. Retrieved from www.effectivecamp.com.

Sweatman, M. and Heintzman, P. (2004). The perceived impact of outdoor residential camp experience on the spirituality of youth. World Leisure 1, 23-31. 
Journal of Youth Development | http://jyd.pitt.edu/ | Vol. 13 Issue 1-2 DOI 10.5195/jyd.2018.556 Uniqueness of Christian Summer Camp Experiences

Thompson, M. (2012). Homesick and happy: How time away from parents can help a child grow. New York: Ballantine Books.

Thurber, C., Sanlin, M., Scheuler, L., and Henderson, K. (2007). Youth development outcomes of the camp experience: evidence for multidimensional growth. Journal of Youth Adolescence 36, 241254.

Yust, K. M. (2006). Creating an idyllic world for children's spiritual formation. International Journal of Children's Spirituality 11, 177-188. 